DEPARTAMENTO DE PSICOLOGIA

Curso de Especialização em Psicologia da Saúde

O Acolhimento na Instituição Hospitalar

Desamparo, Humanização e Práticas

Autora: Priscila Silva Bezerra

Orientadora: Sara Ângela Kislanov 


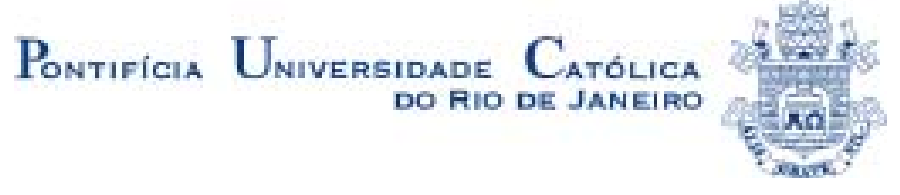

Autora: Priscila Silva Bezerra

\section{O Acolhimento na Instituição Hospitalar Desamparo, Humanização e Práticas}

Monografia apresentada ao programa de Pós-Graduação em

Psicologia da PUC-Rio como requisito parcial para obtenção do título de

Especialista em Psicologia da Saúde

Orientadora: Sara Ângela Kislanov

Rio de janeiro

Abril de 2011

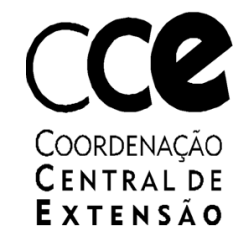




\section{Agradecimentos}

Agradeço à minha família pelo apoio contínuo à minha formação acadêmica.

Agradeço à professora Sara Ângela Kislanov por tudo que me ensinou, sua orientação e paciência.

Agradeço ás minha amigas, principalmente Dayse Rocha, Eliane Luciano, Isaura Rocha e Viviane Dias pelo apoio, ajuda, conversas e risadas.

Agradeço á Deus, minha única certeza. 


\section{Resumo}

O Sistema Único de Saúde foi instituído para dar suporte à efetivação da política de saúde no Brasil, que é um direito de todos os cidadãos. Contudo, diante da qualidade dos serviços, atendimentos e cuidado oferecidos nas instituições de saúde, especialmente a hospitalar, e da dor, do sofrimento e desamparo dos pacientes hospitalizados percebeu-se que além de garantir o acesso universal a estes serviços, era necessário garantir a sua qualidade. Assim, este trabalho visa abordar, discutir e refletir sobre as políticas e dispositivos instituídos pelo Estado que visam a humanização dos modos de atenção e gestão na área da saúde e valorizam o aspecto acolhedor do atendimento.

\section{Palavras-chave}

SUS; hospitalização; desamparo, humanização; acolhimento.

\section{Abstract}

The Health System was established to support the effectiveness of the health policy in Brazil, which is a right for all citizens. However, given the quality of services, treatments and care offered at the health institutions, especially at the hospital, and the pain, suffering and hopelessness of hospital patients it was perceived that in addition to ensuring universal access to these services, it was necessary to ensure quality. This work aims to address, discuss and reflect on the policies and provisions established by the State aimed at the humanization of the form of care and management in the Field and that value the friendly aspect of care.

\section{Keywords}

Health System; hospitalization; helplessness, humanization; host 


\section{Sumário}

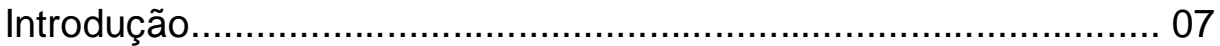

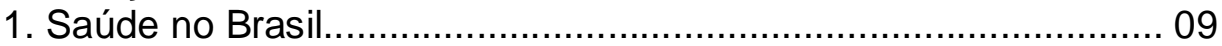

1.1. Histórias, Construções e Políticas.......................................... 09

1.2. SUS e a Humanização..................................................... 14

2. (Des)Humanização e Desamparo............................................ 18

2.1. O Desamparo............................................................ 22

3. Acolhimento......................................................................... 26

3.1 Conceitos e Definições..................................................... 26

3.2 Práticas e Desafios.............................................................. 30

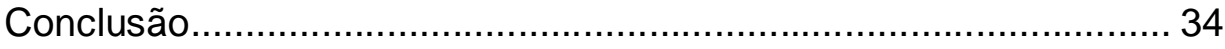

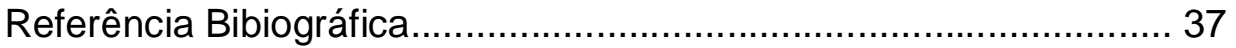




\section{Introdução}

Um marco na política do Estado brasileiro, o Sistema Único de Saúde (SUS), reorganizou todo o sistema, os serviços e as práticas de saúde. Através de seus princípios doutrinários de universalidade, integralidade e equidade, garantiu aos cidadãos o acesso sem discriminação as ações e serviços de saúde, a prestação continuada destes serviços, considerando as várias dimensões do processo saúdedoença, e a prioridade de acesso aos grupos populacionais que enfrentam maiores riscos.

Como a consolidação do SUS é um processo em andamento, outras questões se mostraram tão importantes quanto os princípios regulamentados inicialmente. Mais do que garantir o atendimento, também deve ser garantida sua qualidade. Então, a participação, o protagonismo dos sujeitos, co-responsabilidade e o estabelecimento de vínculos solidários passam a ser priorizados pelo Ministério da Saúde, que implementou o Programa Nacional de Humanização da Assistência Hospitalar e a Política Nacional de Humanização da Atenção e Gestão do SUS. Humanizar e acolher tornaram-se palavras de ordem e ações a serem praticadas por todos nos serviços de saúde.

Foi conferida grande importância a necessidade do acolhimento, termo que passa a ser amplamente defendido e utilizado pelos profissionais de saúde. Contudo, este amplo uso acarreta em uma banalização da ação e do termo, provocando um esvaziamento dos mesmos, originando reflexões e questionamentos. Questionar e refletir sobre o que é o acolhimento, o motivo e importância de se acolher um paciente, como este é realizado e se ele está presente nas práticas de saúde são os objetivos a serem alcançados por este trabalho

Devido a amplitude do assunto, interesses acadêmicos e acesso ao campo de estudo, esta temática será abordada considerando questões majoritariamente referentes ao hospital. Para tal, será apresentada uma revisão bibliográfica e a metodologia a ser utilizada se constituíra de minhas observação e vivências como psicóloga de uma instituição hospitalar.

Esta instituição é um hospital geral, público, localizado na Zona Oeste do município do Rio de Janeiro. Os serviços de saúde oferecidos envolvem assistência ambulatorial, emergencial e hospitalar, sendo disponibilizados 219 leitos, que são divididos entre as clínicas médica, cirúrgica, obstétrica e o Centro 
de Tratamento Intensivo. Trabalho como psicóloga nesta instituição há aproximadamente um ano, fazendo parte de uma equipe composta por médicos, fisioterapeutas, fonoaudiólogos, nutricionistas, dentistas, enfermeiros, assistentes sociais, entre outros. Deve-se ressaltar que no decorrer deste trabalho esta instituição será referida como Hospital X.

Para o melhor desenvolvimento e compreensão deste assunto, será abordado no primeiro capítulo o contexto sócio-histórico-cultural em que foi criado o Sistema Único de Saúde e o que propiciou o surgimento das demandas por humanização e acolhimento deste Sistema. No segundo capítulo será visto porque estas questões se tornaram extremamente importantes e como é possível entendê-las a partir dos aspectos institucionais dos serviços de saúde, das práticas dos profissionais destes serviços e da situação, vivência, sofrimento e desamparo do paciente. Já no terceiro e último capítulo será feita uma reflexão sobre o acolhimento, seus conceitos, objetivos e como ele está presente na prática de um psicólogo e no cotidiano de uma equipe multiprofissional de saúde. 


\section{1 \\ Saúde no Brasil}

\section{1}

\section{Histórias, Construções e Políticas}

De acordo com a Constituição da República Federativa do Brasil de 1988, a saúde é um direito de todos e este deve ser garantido pelo Estado. O Sistema Único de Saúde (SUS) é, então, instituído para dar suporte à efetivação da política de saúde no Brasil. Contudo, existia, neste período, todo um contexto que propiciou a instituição deste direito e deste sistema. Entender este quadro é essencial para se entender o SUS, seus princípios, diretrizes e políticas, entre estas, será destacada neste capítulo a Política Nacional de Humanização da Atenção e Gestão do SUS .

A história das políticas de saúde está diretamente associada a história do Brasil e sua constituição como Estado-Nação. Segundo Baptista (2005), as primeiras ações de saúde pública foram implementadas devido a vinda da família real para o Brasil em 1808 e tinham como objetivo manter uma mão-de-obra saudável capaz de suprir os negócios da realeza. Com esta mudança, as condições de vida nas cidades tornou-se uma preocupação, foi estimulada a vinda de médicos para o país e foi iniciado um projeto de institucionalização da saúde no Brasil.

Neste período, ocorreu a normalização da prática médica profissional, sendo controlada as práticas dos curandeiros, barbeiros e jesuítas junto à população. Esta regulação proporcionou a constituição de hospitais públicos, dirigidos por médicos ${ }^{1}$, que atendiam a necessidade do Estado de controlar doenças consideradas nocivas ao povo. Contudo, estas normalizações e ações na área da saúde deviam atender exclusivamente aos interesses políticos e

1 O hospital era, antes da regulamentação, uma instituição de assistência aos pobres, dirigido por religiosos e filantropos, que estavam no hospital, segundo Foucault (1979), para fazer obra de caridade e garantir a salvação eterna, era um lugar onde a função médica não aparecia.caridade e garantir a salvação eterna, era um lugar onde a função médica não aparecia. 
econômicos do Estado. Este preocupava-se com "a saúde da cidade e do produto; a assistência ao trabalhador era uma conseqüência dessa política" (Baptista, 2005, p.14).

Com a proclamação da República em 1889, um novo ciclo começa e as políticas de saúde obtiveram mais espaço. Foram criados a Diretoria Geral de Saúde Pública e o Instituto Soroterápico Federal (posteriormente nomeado de Instituto Oswaldo Cruz), que eram focados na pesquisa e estudos na área da saúde pública. A partir de 1902, começa-se a sistematizar e organizar o saneamento das cidades.Tais reformas são seguidas por ações na área da saúde e priorizavam o combate a doenças epidêmicas, como a febre amarela, peste bubônica e varíola.

Nesta reforma pode-se destacar o código sanitário, proposto por Oswaldo Cruz em 1904, que instituiu a desinfecção de espaços, instituições e residências, a demolição de edificações consideradas prejudiciais a saúde pública, a notificação de doenças epidêmicas, campanha de vacinação obrigatória e a ação de uma polícia sanitária. Era tarefa desta polícia a identificação de doentes, assim como submete-los à quarentena e tratamento. Contudo, o grande temor neste período não envolvia as condições insalubres de moradia ou as doenças, os maiores medos da população estavam relacionados ao tratamento oferecido nos hospitais, considerados matadouros, ao isolamento dos doentes e à vacinação obrigatória, um ação completamente nova, invasiva, cujo o propósito não foi devidamente explicado para a população.

A saúde pública deste momento, segundo Baptista (2005), estava focada nas ações coletivas e preventivas, o direito à saúde integral não era uma questão e não estava no planejamento dos governantes. Aqueles que não tinham recursos para assistência médica ficavam desamparados.

Sobre este período é interessante notar que a maioria das ações implementadas e presentes no código sanitário ainda são práticas recorrentes na área da saúde pública atual, constituindo o campo preventivo das ações em saúde, e como alguns dos medos da população mencionados ainda ecoam mais de um século depois destes acontecimentos, permeando concepções, preceitos e preconceitos sobre campanhas e serviços oferecidos nesta área.

Já a década de 20 foi marcada por revoltas populares e pelos movimentos anarquistas e comunistas. Estes exigiam do Estado ações mais efetivas na atenção à saúde. Dentro deste contexto, Eloy Chaves, que era chefe de polícia, propôs uma 
lei, em 1923, regulamentando a formação de Caixas de Aposentadorias e Pensões (CAPs). Estas Caixas eram "organizadas pelas empresas e administradas e financiadas por empresas e trabalhadores, em uma espécie de seguro social" (Oliveira \& Teixeira, 1985 apud Baptista, 2005, p. 17).

Os segurados pelas CAPs dispunham de socorros médicos, medicamentos, aposentadorias e pensões para os herdeiros. É importante ressaltar que a CAP foi um primeiro esboço do sistema de proteção social do Brasil e que a assistência à saúde estava restrito a determinados trabalhadores que contribuíam para as Caixas, a assistência era exclusiva para quem tinha a condição de segurado.

Já a década de 30 no Brasil é marcada pelo o governo de Getúlio Vargas. O Estado passa a intervir mais na sociedade e na economia, assumindo um papel regulador. São criados o Ministério do Trabalho , a carteira profissional e uma política de proteção ao trabalhador. O papel das CAPs é ampliado e surgem os Institutos de Aposentadorias e Pensões (IAPs). O diferencial destes institutos é a presença do Estado, que o administra, controla e financia; entretanto, a necessidade de contribuição formal do trabalhador, para que este tivesse direito aos benefícios, foi mantida.

Assim, a cidadania, neste período, era regulada e excludente. Cidadãos eram os trabalhadores que exerciam funções reconhecidas pelo Estado e contribuíam. Todos os outros brasileiros não dispunham dos mesmos diretos e estavam desamparados. Mesmo entre os trabalhadores havia um diferença, as categorias que podiam contribuir mais, recebiam assistências médica e hospitalar melhores.

O sistema de saúde continua sofrendo mudanças e o processo de industrialização, a partir da década de 50, foi um grande responsável por estas transformações. Surge uma crescente classe operária e, por conseguinte, uma demanda maior para os serviços de saúde, que precisam ser expandidos para atende-la. Então, é instituída a prática de convênios com o setor privado e "a assistência torna-se mais cara e o hospital, o principal ponto de referência para a busca de um atendimento em saúde" (Baptista, 2005 20). Assim, surgem os grandes hospitais, com assistência especializada e aparatos tecnológicos.

As políticas de saúde continuam dicotomizadas, uma objetivando a saúde pública e com ênfase na prevenção de doenças transmissíveis e a outra visando a saúde previdenciária, restrita aos que podiam contribuir. Todavia, havia uma 
preocupação comum destas com o nível de saúde da população, que correspondia a mão-de-obra disponível, estando atrelada ao desenvolvimento do país. Estas políticas eram instrumentos de controle do espaço, da circulação de produtos e dos trabalhadores. Além disto, elas mobilizavam recursos e verbas para o Estado, uma vez que estavam vinculadas à criação de postos de trabalho, de industrias de medicamentos e de equipamentos.

Contudo, uma nova forma de organização do Estado surge com o golpe militar de 1964 e o sistema sanitário sofre modificações. A saúde pública é negligenciada, a assistência médica é priorizada, o setor privado cresce e há o aumento da abrangência do sistema previdenciário.

Foi criado o Instituto Nacional de Previdência Social (INPS), que uniformizou os Institutos de Aposentadorias e Pensões. Tal ato gerou insatisfação, uma vez que a assistência dos institutos, inclusive a dos mais ricos, poderiam ser usufruídas por todos os contribuintes, sem restrições. Por conseguinte, os hospitais e serviços considerados melhores ficaram superlotados, grandes filas de espera passou a ser algo comum nestas instituições. Também gerou descontentamento o fato do INPS ser completamente controlado pelo Estado autoritário, tendo os trabalhadores sido afastados das decisões que os afetavam diretamente.

Na década de 70, houve um aumento da demanda pelos serviços do setor saúde, pois os trabalhadores rurais, empregadas domésticas e autônomos também foram incluídos no sistema. O Estado, então, dobrou os gastos com a saúde e contratou serviços privados focados no atendimento hospitalar, reforçando o modelo hospitalocêntrico. Foram realizados convênios com empresas e instituições de saúde e ocorreu, na atenção à saúde, uma cisão entre a assistência pública, deteriorada, e a assistência conveniada.

Devido ao repasse de verbas para o setor privado, a área de saúde pública recebeu poucos investimentos, doenças antes controladas voltaram em epidemias, fazendo com que mais pessoas recorressem aos serviços de saúde, aumentando ainda mais os referidos gastos e a necessidade de repasse de verbas. Ocorreu também, neste período, o aumento da pobreza e da desigualdade social.

Diante deste cenário, uma crise era iminente e o governo militar, então, estabeleceu o II Plano Nacional de Desenvolvimento e a política de abertura do governo, como estratégias de manutenção deste. Este plano tinha como meta o 
desenvolvimento social, que estaria atrelado ao desenvolvimento econômico. Já o processo de abertura foi responsável por diminuir a forte repressão exercida pelo Estado autoritário, possibilitando a expressão gradativa dos movimentos sociais.

Esta recente e progressiva liberdade para reivindicar possibilitou o crescimento do movimento sanitário. Este movimento, também chamado de reforma, nasceu nas universidades brasileiras, exerceu oposição técnica e política e "lutou com letras e palavras, visando conquistar espaços, através das críticas (na maioria das vezes pontuais) ao sistema de saúde nacional e ao modelo políticoeconômico brasileiro" (Bertone, 2002, p.16).

O movimento sanitário era composto por intelectuais, profissionais de saúde, intelectuais, organizações populares e membros da própria burocracia estatal. Eles defendiam e agiam em prol da universalização do direito à saúde, que extinguiria a lógica da cidadania regulada e excludente, da integração das ações de prevenção e assistência médica e da criação de um sistema que integrasse o Ministério da Saúde, focado na prevenção, e o Instituto Nacional de Assistência Médica Social (INAMPS), órgão criado em 1977 e responsável por coordenar as ações de saúde no nível médico-assistencial da previdência social.

Em 1979 a Câmara dos Deputados promoveu o I Simpósio sobre Política Nacional de Saúde, que foi um importante acontecimento para a reforma sanitária, uma vez que abordou questões e chegou a conclusões favoráveis a mesma. Ocorreram também diversas mudanças no INAMPS, durante a década de 80, voltadas para a almejada universalização do atendimento.

Outro fato marcante foi $8^{\circ}$ Conferência Nacional de Saúde em 1986, que teve como resultado a implementação do Sistema Unificado e Descentralizado de Saúde (SUDS). Deve-se destacar que nesta conferência foi formada as bases para a formulação da seção concernente à Saúde da Constituição de 1988, que a tornou um direito de todos e dever do Estado.

Posteriormente a criação do SUDS, ocorreu a incorporação do INAMPS ao Ministério da Saúde e finalmente em 1990 a Lei Orgânica da Saúde, Lei n 8080, e a Lei $\mathrm{n}^{\circ} 8142$ fundou e regulamentou, respectivamente, o Sistema Único de Saúde, caracterizado por ser participativo, com controle social sobre as políticas e ações na esfera da saúde.A partir de então, inúmeras leis e resoluções o operacionaliza e o regulamenta.

É importante ressaltar que a construção do SUS não deve ser tomado como 
um processo linear, apesar de este capítulo ter sido formulado desta forma devido a um recurso metodológico. Assim, segundo Campos (2003), a partir dos objetivos dos grupos em luta é traçada a trajetória das políticas de saúde e a cada momento ocorre a conformação do sistema de acordo com estes objetivos, não ocorrendo uma evolução natural de fatos.

\section{2}

\section{SUS e Humanização}

O Sistema Único de Saúde baseia-se em uma concepção ampliada de saúde, incluindo aspectos econômicos, sociais, culturais e bioecológicos, e possui, de acordo com Vasconcelos \& Pasche (2006), uma visão abrangente e integrada das ações e serviços de saúde, superando a visão que enfoca a saúde pela ausência de doenças.

De acordo com estas visões, concepções e contextos social e histórico, foram enunciados os princípios doutrinários do SUS, que consistem na Universalidade, que assegura o direito e o acesso à saúde a todos os cidadãos, sem discriminação; na Integralidade, que garante o acesso a um conjunto articulado e contínuo de ações e serviços, visando a promoção, a proteção, a cura e a reabilitação de cada indivíduo e da população; na Equidade no acesso aos serviços de saúde, seria o princípio relativo a Igualdade, contudo há prioridade na oferta de ações e serviços para parcela da população que enfrenta maiores riscos.

Além destes princípios, também foram estabelecidas diretrizes organizativas do SUS e as mais importantes são a Descentralização, que tem como ênfase a municipalização da gestão dos serviços e ações de saúde; a Regionalização, que objetiva a distribuição mais racionalizada e equânime dos recursos assistenciais; Hierarquização, que visa ordenar o sistema por níveis de atenção e estabelecer fluxos assistenciais da atenção básica aos serviços mais especializados; Participação Comunitária, que garante a participação social na gestão dos serviços de saúde e vem atender a demanda por uma democracia participativa; Integração, que tem como pressuposto a formação de um rede assistencial integrada composta pelas ações entre os subsistemas e pelos serviços do SUS. 
Apesar dos princípios e diretrizes estabelecidos, O Sistema Único de Saúde é um processo ainda em construção. Inicialmente, segundo Trad (2006) foi privilegiado neste processo aspectos de caráter jurídico e legal objetivando a garantia dos direitos e a operacionalização destes.

A ênfase em torno da redefinição das práticas de saúde e das relações sociais no interior do sistema só ocorreu mais recentemente. Com predomínio, neste caso, de iniciativas racionalizadoras e de cunho normatizador. A constatação desse quadro tem fortalecido a discussão em torno do resgate da ética no cuidado e da valorização das dimensões relacionais e subjetivas das práticas de saúde. (TRAD, 2006, P.185)

Partindo-se deste novo foco e problematização, o princípio da Integralidade teve seu sentido ampliado. Além da organização e prestação de serviços em todos os níveis de atenção, essa diretriz passou a abarcar como o indivíduo é atendido, se ele é visto em sua totalidade, portador de singularidades e necessidades particulares, e se a doença é compreendida a partir dos seus aspectos social, econômico, político e psicológico, não somente o biológico.

Assim, a Integralidade pode ser tomada como uma ética, "um valor que pretende construir as políticas, os processos de trabalho e as ações propriamente ditas, a partir da centralidade do usuário e dos sujeitos envolvidos na ação" (SPINK, 2007, p.47). Dessas concepções, decorreu a noção de humanização do sistema e das ações de saúde, que visa reorganizar todo o processo de trabalho, formando e qualificando profissionais e garantindo os direitos e a cidadania dos usuários $^{2}$. A questão não estava mais centralizada na oferta de serviços e sim no encontro entre os profissionais de saúde e o usuário em diferentes contextos de atenção.

Esta noção foi legitimada quando o Ministério da Saúde regulamentou, em 2000, o Programa Nacional de Humanização da Assistência Hospitalar (PNHAH) e a $11^{\circ}$ Conferência Nacional de Saúde a colocou em pauta. O PNHAH é uma política ministerial que se "destina promover uma nova cultura de atendimento à saúde" (MS, 2000). O objetivo fundamental deste Programa seria o de aprimorar as relações entre usuários e profissionais, que seria o campo das interações face-aface, entre o hospital e a comunidade, que corresponderia ao campo das interações

2 Será utilizado o termo usuário para designar o sujeito-cidadão que utiliza os serviços de saúde como um direto social e deve, segundo Trad (2006 In Deslandes, 2006), ser distinguido da noção de cliente ou consumidor, que reforçam uma idéia mercantilista. 
sociocomunitárias, e as relações entre os profissionais com o propósito de melhorar a "qualidade e à eficácia dos serviços prestados por estas instituições" (MS, 2000). Posteriormente, o PNHAH foi substituído por uma perspectiva transversal, isto é, constituindo uma política de assistência e não mais um programa específico.

Deste modo, a Política Nacional de Humanização da Atenção e Gestão do SUS (HumanizaSUS) foi instituído pelo Ministério da Saúde em 2003 . Esta Política defende um SUS mais humano, uma vez que este deve ser construído com a participação de todos e comprometido com a qualidade dos seus serviços e com a saúde integral para todos e cada cidadão. Ela "tem o objetivo de efetivar os princípios do Sistema Único de Saúde no cotidiano das práticas de atenção e de gestão, assim como estimular trocas solidárias entre gestores, trabalhadores e usuários para a produção de saúde e a produção de sujeitos" (MS, 2003). Busca-se valorizar o diálogo, os sujeitos e as trocas, estabelecendo uma nova ordem nas relações, o usuário e o que ele traz é tão importante quanto os profissionais, seus saberes e aparatos tecnológicos.

O HumanizaSUS objetiva ainda fortalecer iniciativas de humanização; desenvolver tecnologias relacionais e de compartilhamento de práticas; aprimorar, oferecer e divulgar estratégias e metodologias que visam mudanças nos modelos de atenção e gestão; contagiar trabalhadores, usuários e gestores com os preceitos da humanização; entre outros. Entre os resultados almejados por esta Política destacam-se a ampliação do acesso aos serviços, a implantação de um modelo de atenção com responsabilização e vínculo, a garantia dos direitos dos usuários, a valorização do trabalho na saúde, a gestão participativa dos serviços e o atendimento acolhedor e resoluto.

Deve-se ressaltar que o modelo de atenção está diretamente relacionado ao modelo de gestão. Assim, as almejadas mudanças nos modos de atender implicam necessariamente mudanças nos modos de gerir a atenção. Contudo, o que se observa são usuários reivindicando atenção com acolhimento, profissionais clamando por melhores condições de trabalho e gestores que apregoam a importância da humanização, mas que adotam medidas que não colocam em questão os modelos de gestão instituídos. A Política de Humanização não é vista como um todo e perde seu caráter ampliado, que busca tanto garantir os direitos dos usuários e trabalhadores quanto apontar diretrizes e dispositivos clínicos e 
políticos, o que dificulta que seus objetivos e esperados resultados sejam alcançados.

Considerando este cenário, será realizada uma discussão mais aprofundada sobre estes dispositivos, particularmente o relacionado ao aspecto acolhedor do atendimento. Uma vez que, o acolhimento é um dispositivo tecnológico relevante nas propostas de humanização, que ganhou destaque recentemente e tornou-se um termo utilizado de modo recorrente nos serviços e ações de saúde.

Contudo, antes de abordarmos este tema atual e amplo, é preciso enterder, a partir das práticas dos profissionais, das particularidades das instituições de saúde e do cuidado que é dispensado aos usuários, porque humanizar passou a ser uma política de extrema importância para o SUS e acolher um verbo a ser conjugado diariamente e a todo momento. Assim, no próximo capítulo será feito um aprofundamento destas questões. 


\section{2}

\section{(Des)Humanização e Desamparo}

Humanização não é uma proposta que ocupa somente o campo das idéias, ela é uma política que precisa ser implementada, estimulada, adotada e estar presente no cotidiano das instituições. Diante disto, é preciso refletir e delimitar que instituições de saúde são estas e porque humanizar e acolher tornaram-se ações extremamente importantes, defendidas e desejadas.

Os serviços de saúde disponíveis para os cidadãos brasileiros têm suas particularidades e segmentações. Existe uma parcela que seleciona profissionais renomados, escolhe equipamentos sofisticados que alimentam instituições de alto padrão tecnológico e são utilizados por pessoas de maior poder aquisitivo. Neste grupo, de acordo com Minayo (2006), o cliente é tratado com reverência; contudo, ainda prevalece na relação entre usuário e profissional a objetividade tecnocientífica, que faz parte da formação e da prática deste, e o saber médico é mantido à distância.

Outra parcela corresponde à medicina de grupo ou individual através dos planos e contratos de saúde. Neste caso, o usuário é tomado como um cliente pagante que é atendido de acordo com suas posses. Em caso de doença, os serviços oferecidos não são pautados nas necessidades do usuário ou no cuidado, mas sim nos custos para as empresas e nas restrições dos planos.

Uma terceira parcela é o da saúde pública, que é a enfatizada por este trabalho, nesta as relações não são perpassadas pela lógica de mercado e estabelecidas entre cliente e prestador de serviço; entretanto a situação dos usuários deste serviço é a mais difícil, segundo Minayo (2006). Existe uma grande disparidade entre a proposta constitucional, princípios e diretrizes do SUS e a realidade vivida pelos cidadãos, que se deparam com restrições e escassez. Diante de tal quadro, a humanização dos cuidados e acolhimento podem ser vistos como necessidades supérfluas dentro de um serviço precário.

No entanto, existem movimentos que reconhecem a importância destas 
ações e buscam mobilizar as subjetividades dos profissionais e usuários. Uma vez que, na maioria dos casos o caráter desumanizador dos serviços não é exclusivamente ocasionado pela escassez ou falta de recursos. Suely Deslandes (2006) destaca o trabalho da socióloga Jan Howard na conceituação e análise de práticas ditas como humanizadoras e desumanizadoras.

Um dos primeiros conceitos de desumanização desenvolvido seria o de tratar sujeitos como coisas, que aponta o fato de os doentes serem tratados como objetos da intervenção clínica e vistos como portadores de necessidades padronizadas, sendo estas determinadas por regras institucionais e o saber médico. A conseqüência de tal tratamento é "a destituição de poder da pessoa doente, além do não reconhecimento dos seus sentimentos, levando a uma ausência de reciprocidade com seus cuidadores" (Deslandes, 2006, p. 37).

Pode-se exemplificar as conseqüência citadas através do seguinte caso: pais de um bebê internado expressam o desejo de sair à revelia do Hospital X por não entenderem o porquê do filho ainda estar hospitalizado. Eles são agressivos com o médico, que diz que nada pode fazer. A psicóloga está presente neste momento e atende esta família. Eles afirmam que só queriam que alguém "falasse direito" com eles, agradecem pela a compreensão de suas preocupações e decidem que a filha permanecerá no Hospital X.

Os sujeitos seriam vistos como problemas a serem resolvidos, reduzindo o sujeito doente à sua patologia. As necessidades subjetivas e os conflitos deste seriam desconsiderados, uma vez que as intervenções concebidas e realizadas são centradas na doença e não no paciente como um todo. Ainda perpassa nesta lógica a idéia de pessoas sem escolha, esta concerne tanto aos usuários que não tem autonomia sobre seu corpo e sua doença quanto aos profissionais engessados nos paradigmas da objetividade e da neutralidade das Ciências Biológicas.

Assim, a tecnologia pode ser um fator que contribui para a desumanização, uma vez que, a partir do paradigmas citados, o cuidado é majoritariamente realizado através de máquinas e procedimentos. As informações consideradas de extrema importância seriam provenientes dos resultados de exames e a interlocução entre equipe e usuários seria praticamente dispensável, pois estes últimos não seriam vistos como portadores de um saber, pelo menos não de um saber que seja considerado confiável ou válido para a equipe de saúde.

Outra prática desumanizadora corresponde a tratar certos usuários como 
pessoas de menor valor, esta prática pode ser mais facilmente encontrada em serviços públicos. Ocorre nestes casos uma atribuição de "status e hierarquia num dado sistema social, em que determinados indivíduos e grupos seriam vistos como "não-pessoas" ou pessoas cujo valor seria considerado inferior ao das demais" (DESLANDES, 2006, p.38). No cotidiano do referido hospital público X pode-se observar que o tratamento dispensado aos custodiados que necessitam de cuidados, usuários de drogas, pacientes psiquiátricos ou mesmo aqueles com baixo nível de formação escolar é diferenciado. Estes sujeitos são destituídos de um saber, são tomados como não capazes de entender o que se passa nos próprios corpos e vidas, não têm autonomia sobre estes, não precisando ser informados sobre as intervenções traçadas para eles, ou não são vistos como uma prioridade para a equipe.

O isolamento também é uma prática desumanizadora dos serviços de saúde, principalmente os que envolvem internações hospitalares, uma vez que expressa a "despersonalização, reclusão, solidão e não-reciprocidade entre pessoas doentes e seus cuidadores no sistema de saúde" (DESLANDES, 2006, p. 38). Quando o sujeito é internado em uma instituição hospitalar, ele passa a ser reconhecido por sua doença, número do leito e registro do prontuário. Assim, seu nome, seus vínculos, seu sistema de relações e suas necessidades são dados de menor significância, ou mesmo insignificantes, no cotidiano destas instituições.

O caso da paciente $\mathrm{W}$, de 10 anos, exemplifica esta prática, visto que ela está hospitalizada há mais de três meses e recebeu o diagnóstico de Fibrose Cística. Os médicos responsáveis afirmam que esta precisa ser transferida para um hospital que ofereça um tratamento especializado. Criança e mãe aguardam esta transferência há um mês, esta afirma que está cansada de cobrar e sente que não é escutada. A equipe de enfermagem reclama que paciente é manhosa e alega que os médicos não estabelecem um contato regular com a instituição que a receberá. Ao ser atendida pela psicóloga, W relata "que a coisa que mais queria na vida era encontrar sua melhor amiga”, o que não é possível desde o dia que foi internada. Para a paciente, falar sobre seu sofrimento é falar sobre a perda dos vínculos perdidos, o que não é uma questão relevante para a maioria dos profissionais envolvidos neste caso.

Deve-se ressaltar que as práticas citadas nos parágrafos anteriores não estão diretamente relacionadas com a falta de recursos, escassez de verbas ou com 
a precariedade dos equipamentos, materiais e instalações das instituições de saúde (apesar de não ser possível desprezar a significância e importância destes fatores), o que existe, nas referidas situações, é uma precariedade nas relações. Este aspecto também foi destacado no documento oficial do Programa Nacional de Humanização da Assistência Hospitalar, que ao discorrer sobre a insatisfação dos usuários, afirma que

$\mathrm{Na}$ avaliação do público, a forma do atendimento, a capacidade demonstrada pelos profissionais de saúde para compreender suas demandas e suas expectativas são fatores que chegam a ser mais valorizados que a falta de médicos, a falta de espaço nos hospitais, a falta de medicamentos etc. (MS, 2000, p.05).

Foi observado que os cuidados prestados nos serviços públicos de saúde são precários, desrespeitosos e violentos. Segundo Deslandes (2004), a violência pode ser física e psicológica, sendo decorrente de maus-tratos e da negação de direitos básicos dos cidadãos, ou simbólica, que se apresentaria nas situações em que os usuários não tem suas demandas e expectativas compreendidas. Neste caso, as necessidades emocionais e culturais destes usuários não são reconhecidas. Além disto, ocorre a imposição de comportamentos e valores morais que são considerados melhores para os usuários, independente da crença, necessidade e desejo destes.

A violência simbólica é extremamente interligada à instituição hospitalar, uma vez que esta impõe aos pacientes o isolamento, a despersonalização e "a submissão disciplinar de seus corpos (e subjetividade) a procedimentos que sequer compreendem" (DESLANDES, 2004, p.09). Ao ser admitido em uma instituição hospitalar, o sujeito passa a ver visto como o doente, o número do seu leito passa a ser mais importante do que seu nome, ele é submetido as regras desta instituição e ao saber médico, toda sua rotina é alterada, a perda dos vínculos constituídos não é uma questão, todos na equipe parecem saber e estabelecer o que é o melhor para ele e não há espaço para choro, reclamações e medos no cuidado que é dispensado à este sujeito-paciente-doente.

Nos casos em que este sujeito expressa seus sentimentos, seus temores, suas insatisfações, quando este demanda mais atenção ou informação do que recebe, é agressivo ou quando há uma recusa em aceitar um procedimento, as reações dos profissionais observadas no Hospital X envolvem fazer calar, rebater, ignorar ou considerar que este é um caso para o psicólogo, que é visto como aquele que acalma os ânimos, "apaga os incêndios" e que de alguma forma irá 
fazer cessar aquilo que não quer ser escutado por esta equipe e que acarreta em sofrimento para a mesma.

Esta censura pode ser constada no seguinte caso: mulher é vista sentada sozinha no corredor do Hospital X chorando copiosamente. Ao ser abordada por esta psicóloga afirma que foi pedido que saísse da enfermaria, pois seria feito um procedimento em seu filho recém nascido. Relata que nenhuma explicação foi dada e que acredita que seu filho esteja morrendo. Ao ser perguntado sobre o quadro clínico do bebê e ser informado sobre o estado de sua mãe, o médico responsável pede que esta seja chamada. Então lhe informa que tipo de procedimento estava sendo feito (um cateterismo venoso umbilical), diz que ela tem sorte por ele ser capaz de fazer tal intervenção, pois, assim, o RN não precisará ser transferido e manda que esta mãe sente lá fora, fique quietinha e pare de chorar, "pois isto não ajuda em nada". Diante da doença, de intervenções médicas e do medo, o único sofrimento permitido é o silencioso, sendo uma obrigatoriedade guardá-lo para si.

Diante destas práticas desumanizadoras, do isolamento, da submissão, do não-diálogo e da violência que perpassam o tratamento e o cuidado torna-se necessário refletir e questionar como o sujeito, que já está debilitado por uma doença e sofrendo fisicamente e psiquicamente, é afetado por este quadro.

\section{1 \\ O Desamparo}

Sigmund Freud discorre sobre dois tipos de experiência de desprazer, aquele que envolve o acúmulo gradativo de tensão e o súbito desprazer da dor. Nestas duas situações segundo Armony (1998), o sujeito pode viver uma situação de desamparo. Desta forma, "quer o ego esteja sofrendo de uma dor que não pára ou experimentando um acúmulo de necessidades instintuais que não podem obter satisfação, a situação econômica é a mesma, e o desamparo motor do ego encontra expressão no desamparo psíquico" (FREUD,1926[1925] p.193). A maioria dos

pacientes internados em uma instituição hospitalar vivenciam estas duas experiências de desprazer e, assim, de desamparo.

No começo de sua obra, Freud remete o desamparo a incapacidade 
objetiva do bebê em satisfazer por si próprio as exigências das sua necessidades vitais. O recém nascido não é capaz de realizar as ações específicas para conter a irrupção de tensões provindas das suas necessidades, assim, estando em um estado de desamparo. O sujeito internado, de certa forma, se encontraria neste estado, principalmente os que estão imobilizados em seus leitos, incapazes ou sentindo-se assim e totalmente dependentes dos cuidados da equipe de saúde (que utiliza uma noção padronizada das necessidades para determinar e realizar estes cuidados).

Contudo, segundo Pereira (1999), Freud vai colocar a questão do desamparo para além de uma simples regressão a uma fase em que o bebê é totalmente incapaz de sobreviver por seus próprios meios. Assim, não é possível pensar o desamparo somente como um estado inicial afetivo. Esta questão é abordada em "O futuro de uma ilusão", quando Freud fala do desamparo como algo que acompanha o sujeito por toda a sua existência e não como uma etapa ou um momento do funcionamento psíquico que pode ser demarcado no tempo.

Vale ressaltar que em momento algum da obra freudiana, de acordo com Pereira (1999), o desamparo humano é tomado como algo que pode ser totalmente superado. A relação do homem com sua existência sempre seria marcada pela precariedade, pelas falsas ilusões de domínio e pelas tentativas mágicas de proteção contra os perigos. No ambiente hospitalar isto fica mais óbvio, na medida que o paciente é confrontado a todo momento pela precariedade do seu corpo, da sua vida e das sua relações.

O modo de operar o cotidiano destas instituições hospitalares produz sofrimento tanto para os profissionais quanto para os pacientes. Em "O mal estar na civilização", Freud afirma que o sofrimento nos ameaça a partir de três direções, sendo estas fontes do sentimento de desamparo. São elas: de nosso próprio corpo, condenado à decadência e à dissolução, e que nem mesmo pode dispensar o sofrimento e a ansiedade como sinais de advertência; de nossos relacionamentos com os outros homens; e do mundo externo, que pode voltar-se contra nós com forças de destruição esmagadoras e impiedosas.

Já em "O futuro de uma ilusão", Freud discorre sobre as situações com que o homem vai se deparar e que serão geradoras de medos e do sentimento de desamparo. São situações que envolvem elementos que fagem a qualquer controle humano, 
a terra, que treme, se escancara e sepulta toda a vida humana e suas obras; a água, que inunda e afoga tudo num torvelinho; as tempestades, que arrastam tudo o que se lhes antepõe; as doenças, que só recentemente identificamos como sendo ataques oriundos de outros organismos, e, finalmente, o penoso enigma da morte, contra o qual remédio algum foi encontrado e provavelmente nunca será. É com essas forças que a natureza se ergue contra nós, majestosa, cruel e inexorável; uma vez mais nos traz à mente nossa fraqueza e desamparo. (FREUD, 1927, p.27)

O sujeito internado em um hospital, precisa lidar diariamente com estas fraquezas e desamparo. Ele é confrontado com o fato de estar doente, com a fragilidade do seu corpo, com sua impotência e com questões relacionadas com a morte e o morrer. Questões que se colocam de forma pungente, uma vez que a morte está no corredor, na enfermaria, no leito ao lado, ela é uma certeza que torna-se mais perceptível. Na instituição hospitalar, a linha entre saúde-doença e vida-morte é mais tênue.

Freud teria, segundo Pereira (1999), uma grande estima pela Ciência e Razão, uma vez que estas seriam capazes de dar ao homem uma orientação possível, fundada não em ilusões tranqüilizadoras, mas na realidade externa. No entanto, Freud conclui que a Ciência e a Razão não são capazes de dar a resposta última sobre questões cruciais como a do destino e da morte. "Nesses campos, as respostas são sempre precária e dão a impressão de deixarem o essencial de fora" (PEREIRA, 1999, p.145). A partir desta perspectiva, pode-se destacar o desamparo dos próprios profissionais de saúde, que têm suas práticas baseadas na Ciência, na objetividade e na neutralidade e que descobrem que não estão protegidos por elas, que existem frestas pelo qual o sofrimento e o desamparo conseguem penetrar. Isto pôde ser observado de forma clara e contundente em uma situação que envolveu a morte de diversas crianças e adolescentes em um mesmo momento, estando ainda outras gravemente feridas. Os profissionais envolvidos nos atendimentos e nos procedimentos médico estavam emocionados, consternados e sofrendo por estes pacientes.

Diante das práticas desumanizadoras que podem ser observadas no cotidiano da instituição hospitalar, do sofrimento que elas acarretam e da situação dos sujeitos que encontram-se nesta instituição, que precisam lidar com a dor, o medo e o desamparo, tornou-se imperativo definir e defender o estabelecimento e adoção de práticas humanizadoras neste serviço de saúde, entre elas destaca-se, como já foi dito no primeiro capítulo, o acolhimento. 
Assim, no próximo capítulo serão abordados as possíveis definições deste dispositivo tecnológico, o que este envolve, como ele está presente na prática dos profissionais desta instituição, principalmente do psicólogo, e qual é a sua importância para os usuários do Sistema Único de Saúde. 


\section{Acolhimento}

\section{1}

\section{Conceitos e Definições}

O acolhimento é, segundo o Ministério da Saúde, "uma ação tecnoassistencial que pressupõe a mudança da relação profissional/usuário e sua rede social através de parâmetros técnicos, éticos, humanitários e de solidariedade, reconhecendo o usuário como sujeito e participante ativo no processo de produção da saúde". Para o melhor entendimento desta definição é necessário o aprofundamento e reflexão sobre alguns termos utilizados e sobre o que está sendo proposto.

Sobre o aspectos técnicos mencionados, é importante destacar os diferentes tipos de tecnologias que são empregadas no trabalho em saúde, segundo Merhy (1997), estas podem ser classificadas em três categorias: a tecnologia dura, que engloba os equipamentos, normas, rotinas e estruturas organizacionais; a levedura, que refere-se aos saberes profissionais bem estruturados que atuam no processo de saúde; e a leve, que é produzida no trabalho vivo, compreende as tecnologias de relações, de produção de comunicação e diz respeito à produção de vínculos, gestão do processo de trabalho, autonomização e acolhimento.

Desta forma, o acolher é uma tecnologia que tem sido utilizada no movimento que busca mudanças na cultura de atendimento, no modelo de atenção, que não mais seria centrado no médico e na doença, mas sim na pessoa. O acolhimento é aplicado como uma estratégia de organização da assistência, visando a ampliação do acesso e focado no trabalho multiprofissional da equipe e no estabelecimento de relações calcadas em aspectos humanitários de solidariedade e cidadania. O usuário, segundo Filgueiras (2006), deve ser reconhecido como um outro legítimo na relação com a equipe de saúde.

É nesta interação entre os usuários e os serviços de saúde, onde há a possibilidade de escuta, que ocorre o acolhimento. É necessário que exista o legítimo interesse em ouvir o outro e promover o rompimento do monólogo 
daqueles que são considerados detentores do saber-poder. "A mais básica condição de possibilidade da inflexão de saúde na direção do cuidado é o privilegiamento de dimensão dialógica" (AYRES,2006, p.70). Ouvir e fazer-se ouvir, capacidade de escuta, aspectos de um diálogo que é possível entre sujeitos, mas não entre sujeito e objeto.

Em uma tentativa de adotar práticas mais acolhedoras, o diretor do Hospital X cria o 'Bom Dia Direção', um espaço de escuta para os acompanhantes dos pacientes. Uma vez na semana, às oito horas e trinta minutos da manhã, estes podem falar e reclamar sobre a situação dos seus familiares. Este encontro é realizado em um auditório e deve-se destacar que o diretor e os coordenadores de todos os setores (que são obrigados a estar presentes) ocupam uma grande mesa localizada em cima de um tablado. Quando os pacientes e familiares são informados sobre este espaço, a maioria afirma que não está interessada em ir. Eles relatam que não acreditam que algo realmente vai mudar, que sabem que profissionais rebatem ou desmentem o que está sendo dito ou que sentem medo de sofrer retaliações, sendo melhor ficar calado.

Considerando este quadro, nota-se que a direção almejava a criação de um espaço que possibilitasse o diálogo entre os profissionais de saúde e os usuários. Todavia, a hierarquia entre estes sujeitos foi mantida. Não foi possível promover a autonomia, o protagonismo e o diálogo neste encontro, uma vez que os profissionais ainda ocupavam uma posição de portadores do saber-poder. Humanizar e acolher foram ações impostas à eles e o modo de gerir a instituição e a atenção não foi colocado em pauta.

Para que o acolhimento aconteça é necessário que haja uma preocupação com o tipo de escuta que se oferece e com a qualidade desta, isto é, não basta ouvir atentamente e pacientemente o usuário se o objetivo for contornar o que interfere no processo de diagnóstico e tratamento, contornar os 'ruídos' que não estariam estritamente relacionados aos sintomas, sinais e doenças. Quando há uma abertura para o diálogo, no qual não há qualificação da fala do outro, uma triagem de conteúdos considerados mais importantes dentro de um parâmetro tecnocientífico, é possível introduzir novas referências que vão redimensionar o que é necessário fazer. A partir do que é dito e pela presença de um outro sujeito é possível traçar um plano de intervenção, sendo possível, de acordo com Ayres (2006), o surgimento de novos objetos, ou de outros aspectos de um mesmo 
objeto.

Contudo, esta preocupação com o diálogo e o tipo de escuta não é facilmente constatada nas instituições hospitalares, especificamente no Hospital $\mathrm{X}$. Entre as queixas dos usuários destacam-se a falta de informação e o modo que alguns profissionais realizam suas consultas de rotina. Pode ser observado nesta instituição situações em que não há o uso da palavra no contato entre profissional e paciente. Este último é examinado, tocado e abordado por toda equipe multiprofissional, a qualquer momento do dia, sem que haja a necessidade de pedir sua permissão, de explicação ou justificativa para tais atos. É como se houvesse uma obrigação em aceitar os cuidados dispensados e se o paciente os nega "a porta é a serventia da casa", frase proferida por uma profissional ao ser questionada sobre a intervenção determinada e escutar o desejo da paciente de ir embora da instituição.

Esta prática e postura também puderam ser constatadas em outras situações, como a da médica que ao ser questionada por familiar sobre que remédio receitou para sua esposa, que estava desacordada, responde: "ela vai tomar esse remedinho e vai ficar boa". Não satisfeito com a resposta, o marido da paciente pergunta de novo e afirma que é seu direito saber. Então, a médica reage tirando a receita da mão deste, amassando e jogando no lixo. Posteriormente, quando é interpelada por psicóloga e assistente social, nega o acontecido e não há nenhuma conseqüência para suas ações.

Este quadro suscita reflexões no campo da ética, que é um parâmetro presente no conceito de acolhimento, uma vez que para haver preocupação ética é necessário que haja uma preocupação com o outro, que o usuário seja visto como um legítimo outro na relação. O texto "HumanizaSUS - Acolhimento com avaliação e classificação de risco: um paradigma ético-estático no fazer em saúde" (2004), do Ministério da Saúde, apregoa a necessidade de construção de alianças éticas com a produção da vida e que o foco deste processo seja os sujeitos, usuários e profissionais de saúde. "Essas alianças com a produção da vida implicam um processo que estimula a co-responsabilização, um encarregar-se do outro, seja ele usuário ou profissional de saúde, como parte da minha vida“ (MS, 2004).

Este processo incentiva a construção de redes de autonomia e compartilhamento. Uma vez que é estabelecido um vínculo entre os sujeitos 
envolvidos na equação do atendimento, a troca de apoios e o exercício da confiança torna-se possível. Campos (2003 apud ARTMANN \& RIVERA, 2006) afirma que para o usuário este apoio compreende um potencial maior de autonomia, de incorporação de saber, que envolve a aprendizagem, e de segurança. A construção de um vínculo terapêutico possibilita o aumento da autonomia e do protagonismo dos sujeitos no processo de produção de saúde.

Autonomia e protagonismo estes que ainda não são valorizados ou estimulados na prática de alguns profissionais do Hospital $\mathrm{X}$, como pode ser constatado no na fala da mãe de uma criança que apresenta quadro de paralisia cerebral está internada no Hospital X devido a uma Pneumonia. Durante o atendimento, relata que médico realizou a visita de rotina muito cedo, as crianças ainda dormiam, examinou-as sem dizer uma palavra e não deu nenhuma informação aos pais. Ela é responsável pelos cuidados da filha em casa e demonstrava saber detalhes sobre o quadro clínico e tratamento desta. Contudo, estava extremamente preocupada, uma vez que descobriu que mudaram a dosagem da medicação anticonvulsionante de sua filha. Apesar de saber os nomes das medicações, as dosagens e o todo processo para a determinação destas, relata que a equipe médica não queria discutir as implicações destas mudanças com ela e se perguntava o que faria quando fosse para casa, afinal ela é a responsável pela vida de sua filha

A produção de vínculo entre profissionais e usuários é processual e depende do acolhimento, um dispositivo que deve perpassar diferentes espaços na instituição de saúde e deve estar presente em todas as etapas do trabalho, não sendo restrito ao momento da recepção ou responsabilidade de alguns profissionais. Ele deve estar presente na chegada do usuário ao hospital e durante todo o seu percurso nesta instituição.

Segundo o Ministério da Saúde (2004), colocar o acolhimento em ação requer uma transformação no fazer em saúde e implica em uma reorganização do serviço de saúde a partir da reflexão e problematização dos processos de trabalho, possibilitando a intervenção de toda uma equipe multiprofissional; na elaboração de projeto terapêutico individual e coletivo, considerando que o usuário está inserido em um contexto pessoal, familiar e social complexo; mudanças estruturais na forma de gestão do serviço de saúde, ampliando os espaços democráticos de discussão/decisão, dando também lugar ao sofrimento e 
necessidade do profissional; construir coletivamente propostas com a equipe local e com a rede de serviços e gerências centrais e distritais; além dos referidos protagonismo do sujeito no processo de produção de saúde e compromisso com a escuta.

A discussão e reflexão sobre o acolhimento faz emergir a dimensão subjetiva do cuidado, a "importância dos afetos entre humanos numa relação que envolve a dramaticidade da dor e da morte" (Deslandes, 2006, p.44). Através desta discussão, o acolher se afasta do senso comum e ganha enquadramentos teóricos da filosofia, da psicologia e da psicanálise , sendo estes últimos aspectos de extrema importância e relevância para este trabalho.

\section{2}

\section{Práticas e Desafios}

No cotidiano de uma instituição hospitalar, o ato de acolher foi relacionado à figura do psicólogo, como se o atendimento acolhedor fosse de responsabilidade do setor de Psicologia. Além disto, considera-se que o acolhimento é implícito ao atendimento deste profissional. Assim, cabe refletir sobre estas concepções que não correspondem as práticas ou teorias.

No capítulo anterior foram destacados os aspectos desumanizadores da instituição hospitalar e dos serviços de saúde e como o sujeito internado precisa lidar com sua dor, sofrimento, medo, morte e como isto lhe remete a um estado de desamparo. Segundo Calmon (1988), todas as vezes que o sujeito se depara com o afeto do desamparo, principalmente quando ele sente sua sobrevivência ameaçada, seu aparelho psíquico lidará com um nível máximo de excitação, acarretando em um trabalho incessante até que esta tensão possa ser diminuída. Isto só será possível quando suas necessidades de proteção forem satisfeitas.

A respeito deste atendimento das necessidades e sobre o trabalho do psicólogo Winnicott afirma: “o paciente não está lá para trabalhar conosco, exceto quando fornecemos as condições que são necessárias" (Winnicott, 1964 apud Calmon, 1988, p.30). Neste caso, atender a necessidades e exigências do paciente não corresponde a sucumbir a uma sedução ou infantilizá-lo, mas sim trata-se de promover condições satisfatórias para que ele possa se desenvolver 
emocionalmente.

Quando um paciente está vivenciando o estado de desamparo, o tom de voz e o som das palavras são mais importantes, de acordo com Calmon (1988), que o sentido que se queira dar e as interpretações. Assim, uma intervenção possível para o psicólogo em uma instituição hospitalar corresponde ao estabelecimento de um ambiente acolhedor e seguro, que proporcione ao sujeito agir criativamente sobre a experiência que está vivendo, não se submetendo ou assujeitando, sendo capaz de transformar tanto a realidade interna como externa e se implicando no seu adoecimento.

Olhar o paciente, reconhecendo-o com um sujeito e não um objeto, escutálo, dar certas garantias, como garantir a continuidade dos atendimentos e estabelecer vínculos são intervenções e práticas que podem fazer com que o ambiente fique menos ameaçador, a situação menos aterrorizadora e que o paciente sinta-se acolhido. Estas práticas podem ser constatadas nos casos que serão relatados a seguir.

O Serviço Social requisita que o Setor de Psicologia acompanhe o caso de uma paciente que estava decidida a abdicar dos seus direitos parentais para que seu filho fosse adotado. Não foi possível a atender, visto que ela saiu à revelia da instituição. Contudo, o recém nascido ainda precisava ficar internado por dez dias. Assim, o caso continuou a ser acompanhado pela Psicologia. Enquanto segurava, falava e cantava para este bebê, este olhava na direção do rosto desta psicóloga, que retribuía o olhar. Winnicott (1975) discorre sobre a importância deste ato e afirma, ao abordar o desenvolvimento do bebê humano, que "quando olho sou visto; logo existo. Posso agora me permitir olhar e ver" (Idem, Ibdem, p.157). Os atendimentos possibilitavam que este bebê olhasse e fosse visto.

Outro exemplo envolve o seguinte relato: "eu estava muito nervosa, me sentindo insegura, mas com você aí me olhando eu me senti melhor... foi muito mais fácil fazer isso",fala de uma paciente do Hospital X, após trocar a fralda do seu primeiro filho, que nasceu prematuramente, sendo observada pela psicóloga. Este caso remete ao que Winnicott (1983) chama de capacidade para estar só. Diversas experiências levam à formação da capacidade de ficar só, contudo há uma fundamental para o surgimento desta, que é a experiência de ficar só na presença da mãe ou da mãe substituta, isto é, estar só quando mais alguém está presente. Esta capacidade corresponde a um fenômeno extremamente sofisticado e 
que está intimamente relacionado com a maturidade emocional. Ele afirma que esta capacidade é importante para o paciente e que uma sessão silenciosa pode representar uma conquista por parte do paciente, talvez sendo esta "a primeira vez que o paciente tenha tido a capacidade de realmente ficar só" (Idem, Ibdem, p.31)

$\mathrm{O}$ último caso a ser relatado envolve morte e perda. Uma familiar de uma paciente internada no Hospital X, após ao recebimento da notícia de óbito desta, fala sobre sua dificuldade em permanecer "forte" para sua família, da forma que vinha sendo durante aquele dia. Então, segurando fortemente a mão da psicóloga, ela se permite falar sobre o amor que sentia pela sobrinha, chora, grita e consegue expressar seu sofrimento.

Vale ressaltar, que no cotidiano de um hospital, não é possível dizer que um paciente foi acolhido somente por que este foi atendido por um psicólogo. Este profissional está inserido na lógica desta instituição, podendo existir uma demanda por produtividade, a fala do paciente pode ser guiada até um certo ponto que se queira chegar, pode ocorrer a construção de uma proposta terapêutica enredada na doença, não ocorrendo exatamente a escuta deste paciente. Então, o psicólogo não deve ser visto como a personificação do acolhimento.

As práticas de um psicólogo estão diretamente atreladas a sua formação, o mesmo ocorre com todos os profissionais de uma equipe multiprofissional que baseiam seus fazeres nas sua formações. Assim como, todos os profissionais estão inseridos em um contexto institucional. Estes, então, não podem ser vistos como os vilões da história e o acolhimento não pode ser algo que é imposto à eles.

Para que o acolher se torne um verbo a ser conjugado todos os dias e por todos, do servente até ao diretor da instituição hospitalar, é necessário que ocorram mudanças nos currículos das faculdades, que a proposta de educação continuada realmente ocorra, que sejam escutadas as demandas, as necessidades e o sofrimento dos usuários e profissionais.

A humanização e o acolhimento não podem ser imposições de políticos e gestores aos profissionais que estão inseridos no cotidianos das instituições de saúde, esta imposição já se configura como um indício que os objetivos desta política e dispositivo não serão alcançados. Os propósitos e preceitos destes devem ser discutidos, compreendidos e defendidos por todos os envolvidos nesta equação. Deixando de ser vistos como exceções ou coadjuvantes nos serviços de saúde e passando a ser tomados como primordiais para a sobrevivência do SUS. 


\section{Conclusão}

A saúde ser um direito de todos, de acordo com a Constituição de 1988, devendo este ser garantido pelo Estado e a instituição, em 1990, do Sistema Único de Saúde são consideradas conquistas de suma importância para os cidadãos brasileiros. O primordial, naquele contexto social e histórico, era garantir que todos os cidadãos, sem discriminações, tivessem acesso aos serviços de saúde. Contudo, percebeu-se, posteriormente, que somente garantir o acesso universal a estes serviços não sanava os problemas na área da saúde. Também era necessário garantir que estes fossem de qualidade e que atendessem as demandas e necessidades dos usuários.

Partindo desta questão, O Ministério da Saúde realizou uma pesquisa com os usuários das instituições hospitalares, que evidenciou a insatisfação destes com a qualidade dos atendimentos e tratamentos recebidos. Desrespeito, maus tratos e violência faziam parte do cotidiano destas instituições. Diante deste diagnóstico de insatisfação, foi regulamentado, em 2000, o Programa Nacional de Humanização da Assistência Hospitalar, que foi ampliado e substituído, em 2003, pela Política Nacional de Humanização da Atenção e Gestão do SUS.

Esta política de assistência buscou instituir um novo modelo de atenção e gestão, oferecer atendimento de qualidade e resolutivo e articular os avanços tecnológicos com o bom relacionamento, que é pautado na comunicação e no diálogo entre usuários, profissionais e gestores.

Um dispositivo que se mostrou extremamente relevante para os objetivos da Política de Humanização foi o acolhimento, que é uma ação que visa ampliar o acesso e é focada no trabalho multiprofissional da equipe e no estabelecimento de relações calcadas em aspectos humanitários de solidariedade e cidadania.

Humanização e acolhimento passaram a ser ações que precisavam estar presentes no cotidiano das instituições de saúde. Contudo, o que pode ser observado no Hospital $\mathrm{X}$ é uma deficiência do diálogo entre profissionais, usuários e gestores, que incide de forma negativa no cuidado prestado, comprometendo a qualidade do atendimento e imputando sofrimento aos sujeitos envolvidos.

Os gestores determinam os programas e ações que devem ser implantados, os diretor da instituição estabelece que seus funcionários precisam os colocar em prática e, neste processo, profissionais e usuários não são ouvidos. Não é 
estabelecido um diálogo e a hierarquia entre todos os envolvidos é mantida. Desta forma, os objetivos almejados não são alcançados e prevalecem no cotidiano destas instituições práticas desumanizadoras e o não-acolhimento dos pacientes.

Nos casos relatados ao longo deste trabalho, o médico aparece majoritariamente como aquele que ignora o desamparo, o sofrimento, a dor e a perda do paciente que está vivenciando uma hospitalização. Nestes mesmos casos, a psicóloga pode aparecer como aquela que é responsável e capaz de acolher.

Contudo, não se deve generalizar e cristalizar os papéis dos profissionais em uma instituição hospitalar. Os médicos não são os vilões e os psicólogos não são os mocinhos desta história. As práticas de todos os profissionais estão atreladas as suas formações e as interações entre estes e os pacientes são influenciadas por lógicas culturais e organizacionais que precedem este momento do encontro e condicionam, segundo Deslandes (2004), todo um sistema de regras que orienta os modelos de gestão e a lógica de ações dos envolvidos.

Desta forma, o acolhimento somente será uma ação praticada por todos os profissionais quando houver mudanças na formação, desde a graduação, de todos os profissionais que trabalham na área da saúde, assim como, transformações nos campos da política, gestão e organização, promovendo a democratização das estruturas de poder. Também são necessários investimentos na infra-estrutura das instituições, oferecendo melhores condições de trabalho, e que ocorra a valorização dos profissionais de saúde

Além disto, deve-se destacar que o psicólogo não é a personificação do acolhimento em um hospital, não sendo todos os seus atendimentos acolhedores. Acalmar pacientes, funcionando como uma camisa-de-força, "apagar incêndios"e fazer calar o que incomoda a instituição não são obrigações destes profissionais e não são práticas acolhedoras. Quando o profissional julga saber o que é o melhor para o paciente e acredita que sabe resolver seus problemas e conflitos, o acolhimento não é possível. É fundamental escutar os pacientes e saber que é um sujeito, com demandas, necessidades e questões, que está sendo atendido e não um objeto.

Partindo desta disparidade entre o que proposto pelo HumanizaSUS e o que é observado nas instituições de saúde, especialmente no Hospital X, torna-se necessário questionar o que os profissionais sabem sobre este assunto, o que eles entendem por atendimento acolhedor, se isto é uma questão para eles e se 
acreditam na possibilidade de humanizar os serviços de saúde. Assim, esta temática pode e deve ser aprofundada, em um futuro trabalho, através da escuta daqueles que são diretamente afetados por esta política, os profissionais. 


\section{Referências Bibliográficas}

ARMONY, N. (1998), Quem tem medo do Salto Mortal? - Sobre amparo e desamparo. Cadernos de Psicanálise/ Círculo Psicanalítico do Rio de Janeiro, ano XX, no 12/ p.47-56.

ARTMANN, E. \& RIVERA, F. J. U. Humanização no atendimento em saúde e gestão comunicativa. In: DESLANDES, S. F.(Org.). Humanização dos cuidados em saúde: conceitos, dilemas e práticas. Rio de Janeiro: Editora FIOCRUZ, 2006.

AYRES, J. R. Cuidado e Humanização das práticas de saúde. In: DESLANDES, S. F.(Org.). Humanização dos cuidados em saúde: conceitos, dilemas e práticas. Rio de Janeiro: Editora FIOCRUZ, 2006.

BAPTISTA, T. W. F. O direito à saúde no Brasil: sobre como chegamos ao Sistema Único de Saúde e o que esperamos dele. In: EPSJV (Org.) Textos de Apoio em Políticas de Saúde. Rio de Janeiro: Editora Fiocruz, 2005.

BERTONE, A. A. As idéias e as práticas: a construção do SUS. Rio de Janeiro, 2002. 108 p. Dissertação (Mestrado) - Instituto de Medicina Social - Universidade Estadual do Rio de Janeiro.

BRASIL. Constituição da República. Artigos 194, 196. Brasília: Senado Federal, 1988. Disponível em:

<http://www.senado.gov.br/sf/legislacao/const/> Acessado em: 13 de novembro de 2010

BRASIL. Ministério da Saúde. Portal da Saúde. HumanizaSUS. Disponível em:<http://portal.saude.gov.br/portal/saude/cidadao/visualizar_texto.cfm?i $\mathrm{dtxt}=28288>$. Acessado em: 24 de janeiro de 2011.

BRASIL. Ministério da Saúde. Secretaria de Assistência à Saúde. Programa Nacional de Humanização da Assistência Hospitalar /Ministério da Saúde, Secretaria de Assistência à Saúde. - Brasília - DF, 2000.

BRASIL. Ministério da Saúde. Secretaria de Gestão Estratégica e Participativa. A construção do SUS: Histórias da Reforma Sanitária e do Processo Participativo / Ministério da Saúde, Secretaria de Gestão Estratégica e Participativa. Brasília - DF, 2006.

BRASIL. Ministério da Saúde. Secretaria-Executiva. Núcleo Técnico da Política Nacional de Humanização. HumanizaSUS: acolhimento com avaliação e classificação de risco: um paradigma ético-estético no fazer em saúde /Ministério da Saúde, Secretaria-Executiva, Núcleo Técnico da Política Nacional de Humanização. - Brasília - DF, 2004. 
CADERNOS DE PSICANÁLISE/ Círculo Psicanalítico do Rio de Janeiroano XX, no 12 (1998) - Rio de Janeiro: CPRJ, 1979.

CAMPOS, C. E. A. O desafio da integralidade segundo as perspectivas da vigilância da saúde e da saúde da família. In: Ciênc. saúde coletiva, Rio de Janeiro, v. 8, n. 2, 2003. Disponível em: http://www.scielosp.or/scielo.php?script=sci_arttex\$pid=\$1413 $-81232003000200018 \&$ Ing=PT\&nrm=isso. Acessado em 10 de dezembro de 2010.

DESLANDES, S. F.. Análise do discurso oficial sobre a humanização da assistência hospitalar. Ciênc. saúde coletiva, Rio de Janeiro, v. 9, n. 1, 2004 Disponível em: $<$ http://www.scielo.br/scielo.php?script=sci_arttext\&pid=\$1413320040001 00002\&lng=en\&nrm=iso >. Acessado em: 20 de janeiro de 2011.

DESLANDES, S. F.(Org.). Humanização dos cuidados em saúde: conceitos, dilemas e práticas. Rio de Janeiro: Editora FIOCRUZ, 2006.

FILGUEIRAS, S. L. Eu não sou só o HIV que eu tenho: humanização, acolhimento e escuta no atendimento a mulheres que vivem com Aids. In: DESLANDES, S. F.(Org.). Humanização dos cuidados em saúde: conceitos, dilemas e práticas. Rio de Janeiro: Editora FIOCRUZ, 2006.

FOUCAULT, M. Soberania e disciplina. In: Microfísica do poder. Rio de Janeiro: Graal, 1979.

FREUD, S.(1926[1925]). Inibições, sintomas e angústia. Edição Standard Brasileira das Obras Completas de Sigmund Freud, Vol. XXII. Rio de Janeiro: Imago Editora, 1976.

FREUD, S. (1927). O futuro de uma ilusão. Edição Standard Brasileira das Obras Completas de Sigmund Freud, Vol. XXI. Rio de Janeiro: Imago Editora, 1976.

FREUD, S. (1930/1987d). O mal-estar na civilização. Obras Psicológicas Completas de Sigmund Freud, Vol. XXI. Rio de Janeiro: Imago Editora, 1976.

MERHY, E.E. A rede básica como uma construção da saúde pública e seus dilemas. In: MERHY, E.E.; ONOCKO, R. Agir em Saúde: um desafio para o público. São Paulo: Hucitec, 1997.

MINAYO, M. C. S. Dilemas do setor saúde diante de suas propostas humanistas. Ciência e Saúde Coletiva, 9(1): 17-24, 2004.

PEREIRA, M.E.C. Pânico e desamparo: um estudo psicanalítico. São Paulo: Editora Escuta, 1999.

SPINK, M. J. P. (Org.) . A Psicologia em diálogo com o SUS: prática profissional e produção acadêmica. São Paulo: Casa do Psicólogo, 2007. 
TRAD, L. A. B. Humanização do encontro com o usuário na contexto da atenção básica. In: DESLANDES, S. F.(Org.). Humanização dos cuidados em saúde: conceitos, dilemas e práticas. Rio de Janeiro: Editora FIOCRUZ, 2006.

VASCONCELOS C.M \& PASCHE D. F. O Sistema Único de Saúde. In: CAMPOS G.W.S et al. Tratado de Saúde Coletiva. São Paulo - Rio de Janeiro: Ed. Hucitec, 2006, p. 532-62.

WINNICOTT, D. W. O ambiente e os processos de maturação: estudos sobre a teoria do desenvolvimento emocional. Porto Alegre: Artmed,1983.

WINNICOTT, D. W. O brincar e a realidade. Rio de Janeiro: Imago, 1975. 